\title{
Bootstrapping Your Team for Higher Performance
}

Pedersen, Morten Bjerregaard; Pries-Heje, Jan; Stybe, Gita; Johansen, Jørn

Published in:

Systems, Software and Services Process Improvement

DOI:

10.1007/978-3-030-28005-5_13

Publication date:

2019

Document Version

Peer reviewed version

Citation for published version (APA):

Pedersen, M. B., Pries-Heje, J., Stybe, G., \& Johansen, J. (2019). Bootstrapping Your Team for Higher Performance. In A. Walker, R. O'Connor, \& R. Messnarz (Eds.), Systems, Software and Services Process Improvement: 26th European Conference, EuroSPI 2019, Edinburgh, UK, September 18-20, 2019 Proceedings (pp. 163-178). Springer. Communications in Computer and Information Science Vol. 1 No. 1060 https://doi.org/10.1007/978-3-030-28005-5_13

\section{General rights}

Copyright and moral rights for the publications made accessible in the public portal are retained by the authors and/or other copyright owners and it is a condition of accessing publications that users recognise and abide by the legal requirements associated with these rights.

- Users may download and print one copy of any publication from the public portal for the purpose of private study or research. - You may not further distribute the material or use it for any profit-making activity or commercial gain.

- You may freely distribute the URL identifying the publication in the public portal.

\section{Take down policy}

If you believe that this document breaches copyright please contact rucforsk@kb.dk providing details, and we will remove access to the work immediately and investigate your claim. 


\section{Bootstrapping Your Team for Higher Performance}

Pedersen, Morten Bjerregaard; Pries-Heje, Jan; Stybe, Gita; Johansen, Jørn

Published in:

Systems, Software and Services Process Improvement

DOI:

10.1007/978-3-030-28005-5_13

Publication date:

2019

Document Version

Peer reviewed version

Citation for published version (APA):

Pedersen, M. B., Pries-Heje, J., Stybe, G., \& Johansen, J. (2019). Bootstrapping Your Team for Higher Performance. In A. Walker, R. O'Connor, \& R. Messnarz (Eds.), Systems, Software and Services Process Improvement: 26th European Conference, EuroSPI 2019, Edinburgh, UK, September 18-20, 2019 Proceedings (pp. 163-178). Springer. Communications in Computer and Information Science Vol. 1 No. 1060 https://doi.org/10.1007/978-3-030-28005-5_13

\section{General rights}

Copyright and moral rights for the publications made accessible in the public portal are retained by the authors and/or other copyright owners and it is a condition of accessing publications that users recognise and abide by the legal requirements associated with these rights.

- Users may download and print one copy of any publication from the public portal for the purpose of private study or research. - You may not further distribute the material or use it for any profit-making activity or commercial gain.

- You may freely distribute the URL identifying the publication in the public portal.

\section{Take down policy}

If you believe that this document breaches copyright please contact rucforsk@ruc.dk providing details, and we will remove access to the work immediately and investigate your claim. 


\title{
Bootstrapping your team for higher performance
}

\author{
Morten Bjerregaard Pedersen ${ }^{2}$, Jan Pries-Heje ${ }^{1}$, Gita Stybe ${ }^{2}$, and Jørn Johansen ${ }^{3}$ \\ ${ }^{1}$ Roskilde University, Roskilde, Denmark \\ janph@ruc.dk \\ ${ }^{2}$ Danske Bank, Copenhagen, Denmark \\ morp@danskebank.dk; gstybe@danskebank.dk \\ ${ }^{3}$ Whitebox, Hørsholm, Denmark, \\ jj@whitebox.dk
}

\begin{abstract}
In a major IT development organization, individuals were too often working alone and sub-optimizing. Their performance was not anywhere near the desired level. Analysis indicated that this was due to a number of common factors which lacked attention. To address this, a framework with eight factors grounded in cross-disciplinary theory was developed and evaluated in the organization. It emerged that a self-assessment approach to the eight factors, coupled with training in team theory and facilitated workshops can provide significant value. In the paper, we present the overall framework and details of how to apply it. Furthermore, we present relevant examples and lessons learned. We conclude that you can "bootstrap" yourself to become a higher performing team through facilitated self-assessments using the eight factors.
\end{abstract}

Keywords: High performing teams; framework; agile development; self-assessment; case study.

\section{Introduction}

The very first value in the SPI Manifesto (Pries-Heje and Johansen 2010) is that you "must involve people actively and affect their daily activities". Furthermore, some of the underlying principles are to "motivate all people involved" and "create a learning organisation". Typically, the way people become involved is through participation in a software team that develops or updates a piece of software. But how do you ensure that a software team works well, and people are motivated? That is exactly the problem we will look at in this paper using a case study approach (Yin 2017).

The case is Danske Bank - a major Northern European Bank with more than 20,000 employees. More than 3000 IT-developers are employed by the organisation. New IT development takes place in teams, where some are "classic" project teams that ultimately dissolve, and others are permanent and often agile teams. IT is a critical element of banking, why it is important that these teams are productive and perform well.

For many years Danske Bank's IT organisation has tried to understand why some teams are high performing and others are not. In the $2000 \mathrm{~s}$, the IT organisation undertook a comprehensive transformation programme built on the hypothesis that adopting 
project management and software development best practices would yield a significant boost in productivity as well as achieve higher quality and predictability of project deliveries. This programme utilised productivity measurements based on Function Points (Albrecht 1979; Dumke and Abran 2016) and CMMI (Chrissis et al. 2003) measurement of each IT development project based on the thinking that these measurements can be performed objectively.

Since 2003, Danske Bank has used agile ways of working at the team level. In 2017 a transformation based on agile at scale was initiated. This involves both businesses, IT and customer service organisations of Danske Bank with a focus on building the right solutions for the customers, reducing time to market and increasing productivity.

Agile teams are organised into squads, where each squad is responsible for a distinct and cohesive business scope. Squad members are chosen from many different job function backgrounds. Squad members also belong to a chapter, where each chapter is responsible for the professional growth of a specific role, say a software architect. The squads are cross-functional compared to the set-up of a traditional organisation. To solidify the integration between IT and business, squads are organised into customer journey areas. These are jointly led by an IT leader, the business process owner (who is a business manager), and the primary service owner (who is a manager of a customer service function).

In 2016, the Danske Bank organisation conducted a study of its projects (Andreasen and Sørensen 2016), inspired by a similar study at Google (Duhigg 2016; Schneider 2017). The overall conclusion of this internal study was that too often individuals formally working as teams were in reality working alone and sub-optimising. Furthermore, it was found that:

- The real difference between high performing teams and the other teams lay in the behaviour of the team members

- Team synergy stems from being close together on a daily basis and not from team days or team charters

- High performing teams tend to have a stable set of team members over time, where all team members are valued, and they share an agile mind-set

- Management tools such as documentation and workforce allocation plans serve mainly as management tools; they do not foster higher performance

- First level leaders are critical for team performance

The findings from the internal study triggered the study reported in this paper.

Customer satisfaction, availability or down-time of IT solutions, and release frequency are the ultimate measures of performance seen from the perspective of the businesses or customers. It is difficult to determine a causal relation between these measures and specific actions in each team. Although, Jeppe Hedaa (2018) has worked on systematically quantifying proxy measures to that end, he doesn't measure the value delivered by a team. In light of this, we will focus on underlying performance drivers or inhibitors.

The research question addressed is: How can we help teams to become high(er) performing?

In the following section we first present the underlying literature study and in section 3 we present our design science research method. Then, in section 4 , we present the 
framework we have derived as an answer to the research question of how we can help teams. In section 5 and 6 , we go through examples of using the framework and our summative evaluation of the framework. Finally, we discuss and conclude on the findings and specify our contributions to theory and practice in sections 7 and 8 .

\section{$2 \quad$ High Performing Teams}

A team is defined as a group of people working together. "Working together" should not be taken literally. What matters is that they are together in some structure, e.g., organizational unit or office. While they may not be able to switch tasks, they can still spar with each other. A high performing team is a " ... small group of people with complementary skills who are committed to a common purpose, performance goals and approach for which they are mutually accountable" (Katzenbach and Smith 2015). Typically, a high performing team will be top $10 \%-15 \%$ in their field of work.

We know that some project teams perform better than others even when the team members have the same background, demographical characteristics, and experience. An early study by the software guru Gerald Weinberg (1974) found a difference of 1to- 5 in productivity measured by the size of what was produced. Ten years later in a study of seven teams Barry Boehm (Boehm et al. 1984) found the difference to be a factor 3.4. Another sixteen years later when developing the estimation method COCOMO II, the same Barry Boehm (Boehm et al. 2000) concluded that the difference between a top-performing team (in the best 15\%) and an ordinary team (within 90\%) was a factor 3.5.

Hence, an interesting question is what characterizes the high performing teams as well as how they become high performing?

\subsection{What characterizes a high performing team?}

If we start by looking at characteristics, we find that many books on project management and teams (cf. Adair 1986) point to creating a balance between:

- People - those who are in the team

- Tasks - what is lying ahead of team

- Processes - the way we do things in the team

When examining the people dimension, Jeppe Hedaa (2018) says that getting the team in place begins with finding and selecting people who have a strong set of the right skills for the job. It is primarily the ability to learn how to solve problems that is important. Hedaa says: "Every day, employees are constantly presented with challenges and problem-solving tasks whose success depends on their ability to look at problems from different angles and settings - to be creative and learn new approaches" (Hedaa 2018 , p. 57). Hence, the first factor of a high-performing team that we find is: Strong cognitive adaptability and skills.

Regarding the team itself, Belbin (2012) says that a team is not just a group of people with assigned titles - it is a congregation of individuals, each of whom has a role to enact which should be understood by other members. Belbin defines nine roles to be 
enacted in a team. Likewise, Tom Kelley (2005) says that to have a chance of succeeding in an innovation project you need to have a learning role, an organizing role, and a building role enacted in your team. More recently Truss et al. (Truss et al. 2013) furthers this discussion by focusing on the importance of the employee's engagement and implications on performance outcomes. They point out the difference between "being" engaged and "doing" engaged - none of which can be taken for granted. Hence, the second factor we can identify is a Cohesive Team.

One of the things that causes teams to fail is lack of a common vision (Blanchard et al. 2000). Hence, it is important to ensure that the overall mission and vision for the team is translated into a tangible and clear purpose for the work done by everybody in the team. The aim is to attain a goal-oriented culture, where all team members see their own importance for the team success and business value (Snabe and Trolle 2018). Thus, the third factor we find is Clear team priorities.

High performing team members share basic values. They clearly understand their own strengths and weaknesses and they proactively seek the help needed and constructively engage with each other despite differences (Lencioni 2012). This helps them get the right solution to a problem. Key to this is to acknowledge the importance of comembers, as well as other teams, and how they interact socially. The team dynamics must work constructively also under pressure, so that team members are able to maintain delivery pace even under duress (Duhigg 2016). It is the responsibility of every team member to maintain a culture of psychological safety (Duhigg 2016), though this is in particular the responsibility of the leader of the team. A Healthy team culture is the fourth factor that we find.

It is important to make sure that each team member exhibits productive, constructive and respectful behavior. Having the right behavioral traits that fit the type of job and role in the team also helps ensuring that the people in the team are happy and motivated. Appreciating individual strengths and weaknesses of each team member within the team - "we are different yet one", reinforces a sense of equality and trust (Smart 2005). More importantly, it helps the team be united. In a high performing team, trust between members means that members are not intimidated by each other. Equally, because of the clear common purpose, link to mission and a clear understanding of their value-add, they are not intimated by others (McChrystal et al. 2015). Hence Individual responsibility and Personal drive are the next two factors of a high performing team.

One of the most important factors for team performance is easy and quick decision making (Johnson 2018) - preferably in the team or by the 1st level leader. Achieving this is as Morriss (2002) explains a matter of balancing choice and control. In the Toyota Production System (Chiarini et al. 2018), which focuses on creating a qualityfocused culture, each employee is responsible for making the right choices. They thereby take decisions locally. More generally, we find that this is about bringing the decisions closer to where the work is done. On the other hand, when delegating decisions, one should take into account whether the candidate for taking the decision has a sufficient overview and the skills to take the right decision. Hence, Local decision authority is the seventh factor.

The last factor we found in our survey of literature is about having a Proactive rhythm. It is important that the leader takes a holistic view on the overall plan for the 
team. Due focus is clearly required on the immediate deliveries, but this should be done in tandem with an evolution of skills and an evolution of the product or system which the team is responsible for. It may not seem important to do at first as it may look like all focus is needed for a delivery, but it certainly makes it a lot easier to gain momentum on the next delivery, whether it is yours or that of other teams. This enables the team to maintain a proactive rhythm (McChrystal et al. 2015).

In line with Truss et al. (2013) who discusses the importance of employee engagement and implications on performance outcomes, it is very important to note that everyone in the team, i.e., all team members and management, are responsible for all of the above factors and how well they are performed.

\subsection{How do a high performing team evolve over time?}

A team development model - as its name says - is a model of how teams develop and how this development evolves over time. Most models consist of several phases, each with different characteristics and goals. One of the most widespread and well-known team development models dates back to 1965 when Bruce W. Tuckman (1965) identified four stages that a typical team goes through, called Forming, Storming, Norming and Performing. He argued that team members with conscious knowledge of the four phases had the potential to increase performance.

Bion (1961) has a three-phase model with the following contents:

1. Dependency: Team members attach the leader's authority and power

2. Fight or flight: Team members challenge the leader and other members (= struggle) and leave the team (= drain)

3. Pairing: Team members come together in order to overcome fear, e.g., of the unknown

The middle phase of these three is very similar to Tuckman (1965) "Storming" phase. Another three-phase model was developed by Schutz (1982). He calls his phases:

1. Inside or out: the individual decides whether they are part of the team

2. Top or bottom: Who should have power and authority?

3. Close or distant: How much we pledge?

Allan Drexler and David Sibbet, two American psychologists, spent over 10 years studying teams and refining a team development model with seven phases:

1. Orientation

2. Trust Building

3. Goal and role clarification

4. Commitment

5. Implementation

6. High performance

7. Renewal and goodbye

For each phase, there are some things that should be achieved and some symptoms if the phase is not over. These symptoms can be used by the team leader to say "Aha, I can see that I'm missing something. I need to go back to that stage ... and do this and this." 
The Drexler / Sibbet (Drexler et al. 1988; Forrester and Drexler 1999) model is often characterized as 'a ball bouncing', where the peak of the ball bounce symbolizes the team delivering high performance - a high performance team. The four initial phases centers on what it takes for having 'knocked the ball well in the ground', and the remaining three are more result oriented.

The Software Engineering Institute (SEI) developed the so-called Capability Maturity Model CMM which was successfully used all over the world. An improved version is now called the CMMI - Capability Maturity Model Integrated (Chrissis et al. 2003). In the mid-'90s Watts Humphrey and the SEI began to take an interest in team processes. The first edition of a Team Software Process (TSP) model was developed in 1996, and the book on the TSP was published in 1999 (Humphrey 1999).

Although the name TSP suggests that it is a model for software projects, the model is actually applicable to all types of technical development projects where the team solves a major development task together (Humphrey 2006). TSP operates with three real stages:

1. Team formation

2. Team start-up

3. Teamwork

An interesting innovation is called "Load Balancing". Here you focus on whether the team members have enough or too much to do, and if all skills are exploited. Prepare also a critical path analysis, i.e. an analysis of the activities that will delay the entire project if they are delayed.

Periodically you imagine five key questions (Humphrey 2006, p.194):

- Does everyone in the team have a common understanding of belonging and membership?

- Are all team members committed to a common goal?

- Does the team have ownership of processes and plans?

- Do all team members possess the necessary skills and discipline to carry out the plan?

- Is the team committed to doing an excellent job?

Over the years, many others have worked with team models, although the ones we have reviewed above, in our view, are the most prominent.

\section{Research method}

Our research question is how to create high performing teams instead of individuals who work alone and sub-optimizes? We decided to use a case study (Yin 2017) and apply design science research (DSR) (Hevner 2007) as our research methodology. DSR can be understood as an approach where you build and learn. Thus, in order to answer our research question we have built an artefact to help teams and team members realize what they could improve in order to become higher performing.

The reason for choosing DSR as our research methodology is that it combines the need for practical relevance and utility. DSR emphasizes that a design should address a need or a problem and at the same time should "stand on the shoulders" of existing 
research within the problem area (Hevner 2007). Besides having a 'relevance iteration cycle' where you start by identifying a need or a problem you also have a 'rigor iteration cycle' where you identify all relevant academic literature; what do we actually know by now? The artefact that you are building in order to learn can be a product artefact or a process (Walls et al. 1992). We ended up building a combination in the form of a framework and a process for using the framework. March and Smith (1995) argue that when doing DSR one can build and evaluate four things: Constructs; Models; Methods; and Instantiations. As we were taking our outset in a case study at Danske Bank you could say that the framework presented is an instantiation. However, we actually instantiated it in many projects and over many iterations - following the principle of organizational learning from the SPI Manifesto (Pries-Heje and Johansen 2010). We ended up with a Framework Model and a Method for using it, which we believe is of general interest beyond the Danske Bank instantiation.

To answer our research question, we needed to come up with a framework with relevant factors of performance as well as a way of measuring the status in a concrete team and for a specific set of team members.

We applied the iterative approach inherent in DSR to iteratively build and evaluate a framework that we called the High-Performing Essentials Framework" or in short "HiPEFrame". For design evaluation we applied the process recommended by Venable et al. (2016). Thus, we started with formative evaluations at the desk, continued with real teams in the Danske Bank organization, and ended up with summative evaluation in the real context with real teams and a real problem that needed improvement. This way it becomes a naturalistic summative evaluation.

In the following, we report how the resulting HiPEFrame look, how it can be used, and our final summative evaluation in a number of cases.

\section{The High-Performing Essentials Framework (HiPEFrame)}

In the literature review above, we highlighted key references that illustrate particular team aspects. Based on this review, two other references (Andreasen and Sørensen 2016; Tan 2018) as well as interviews with key informants in the Danske Bank organization, we concluded that the reason high performing teams excel amounts to eight essential factors (HiPEFrame):

1. Strong cognitive adaptability and skills: Strong skills with the ability to adopt new topics

2. Cohesive team: Tightly knit team with the ability to stand in for each member

3. Clear team priorities: Shared purpose and aligned operational priorities

4. Healthy team culture: Psychological safety to voice unpopular views and give feedback

5. Individual responsibility: Act responsible for the greater good of the team

6. Personal drive: Desire to make a significant difference

7. Local decision authority: Empower individuals to take decisions according to their merit 
8. Proactive rhythm: Plan holistically ensuring short-term delivery and long-term sustainability

To operationalize this HiPEFrame a new set of workshop concepts were established:

- Leading a high performing team: What should leaders be mindful about.

- Kick-off to become a high performing team. Bring the team together around a common goal.

- Team Insights feedback: Identify improvements for the team based on the eight factors

- Becoming a high-performing team: Deep-dive on the eight factors combined with a Team Insights feedback

As part of this, a Team Insight assessment tool was designed. The purpose of the tool was to help a team gauge itself on each of the eight factors in the framework. To enable this, a survey was created containing a set of statements for each of the eight factors.

For the "clear team priorities" factor we used the following statements:

1. In my team, it is clear who the customers or end-users are and what their needs are

2. The priorities of my team's tasks are transparent

3. I feel that the tasks I am doing are delivering value

4. In my team, we have a direct feedback loop on customer/end-user needs

5. Our performance goals are tied to strategy and business outcomes

6. My individual performance goals are transparent within the team

7. In my team, we share a common set of performance goals

8. In my team, people are transparent with what they are working on

9. I feel my team is supported by the organization

In the survey, the respondent is asked to rate the extent that they perceive a statement is true for their team on a 7-step Likert scale.

Survey responses are only accepted for a team of minimum five people and these are gathered in an anonymized form to mitigate the risk of deducing "who rated what".

With the survey at hand, a spider-web based analysis was designed to identify areas with the largest room for improvement.

In summary, using the Team Insight feedback entailed the following steps:

1. Team responds to survey

2. Coaches analyze responses, distil findings, and outline improvement recommendations

3. Coaches share findings and recommended improvements, and discuss these with the team with the aim that the team reaches a consensus on what to prioritize (preferably just one improvement)

4. The team agrees on next steps regarding the chosen improvement activity

\section{$5 \quad$ Result of using the Framework}

In Fig. 1 we show an example from using the framework. The example shows that based on the team's perception, the two areas "local decision authority" and "clear team priorities" seem to have the largest room for improvement. 


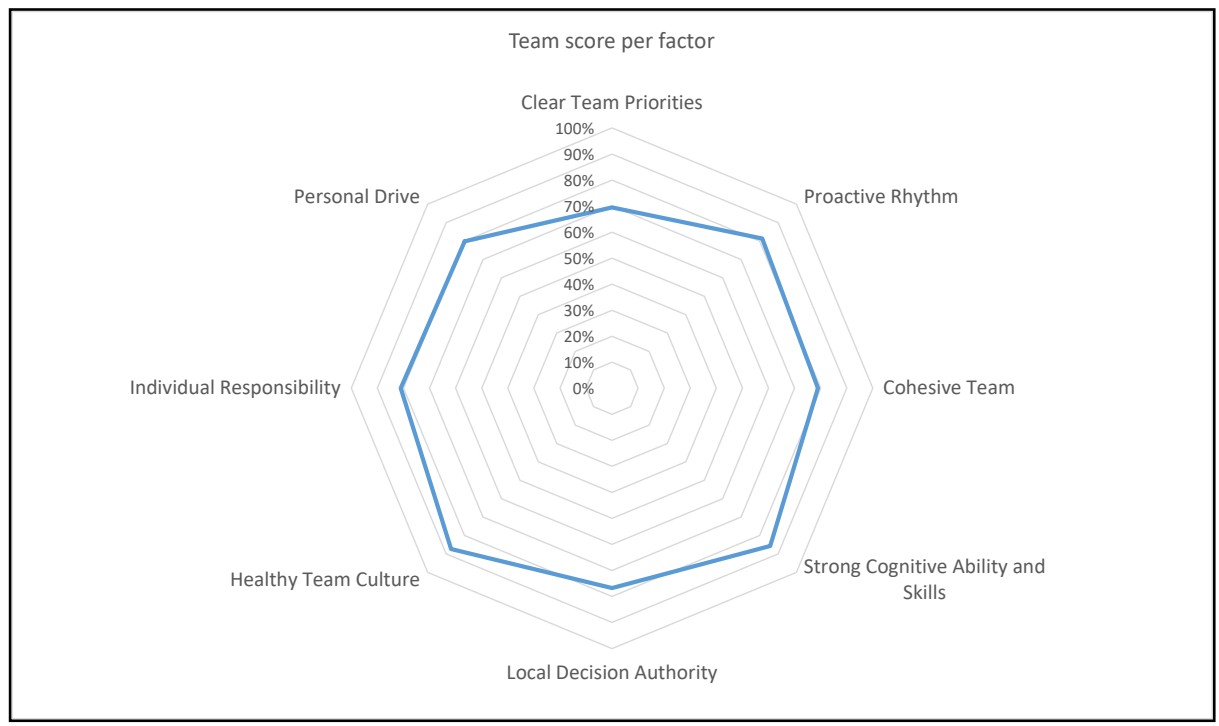

Fig. 1. Team Insight score for each factor

Designated team coaches analyse the survey responses by looking at responses and spider-webs for each of the eight factors. They look for patterns and inconsistencies that cut across statements or factors. To support this analysis, they use spider-webs for each performance factor, where each axis represents one of the statements. An example can be found in Fig. 2. They also explore variance on statements, i.e., the extent to which the respondents agree.

Based on the analysis, the coaches distil findings and improvement suggestions as input for team development. Ultimately, the spider-web data is the voice of the team, and it is key that the team takes ownership of improvement. The coaches facilitate a conversation in the team about the findings and improvements. The goal is that the team builds an internal consensus of what to improve and how to do it.

Example findings:

- The team lacks feedback on its work, and does not see clear organisational context and buy-in

- The team lacks common goals and KPIs

- The team lacks room in its plans to maintain high quality of deliveries and catch up on issues. Their estimation practices are uneven.

- The team appears cohesive with trust among the team members who are open and utilise each other well, and the leader removes roadblocks

- Good leadership and team culture where it is OK to fail and learn and a lot of empowerment

Example improvement suggestion: 
- We believe that the key point for this team is a lack of feeling of how they create value for the organisation. Team should make a draft on what their purpose, mission and value are in the organisation as well as regular feedback with their target groups.

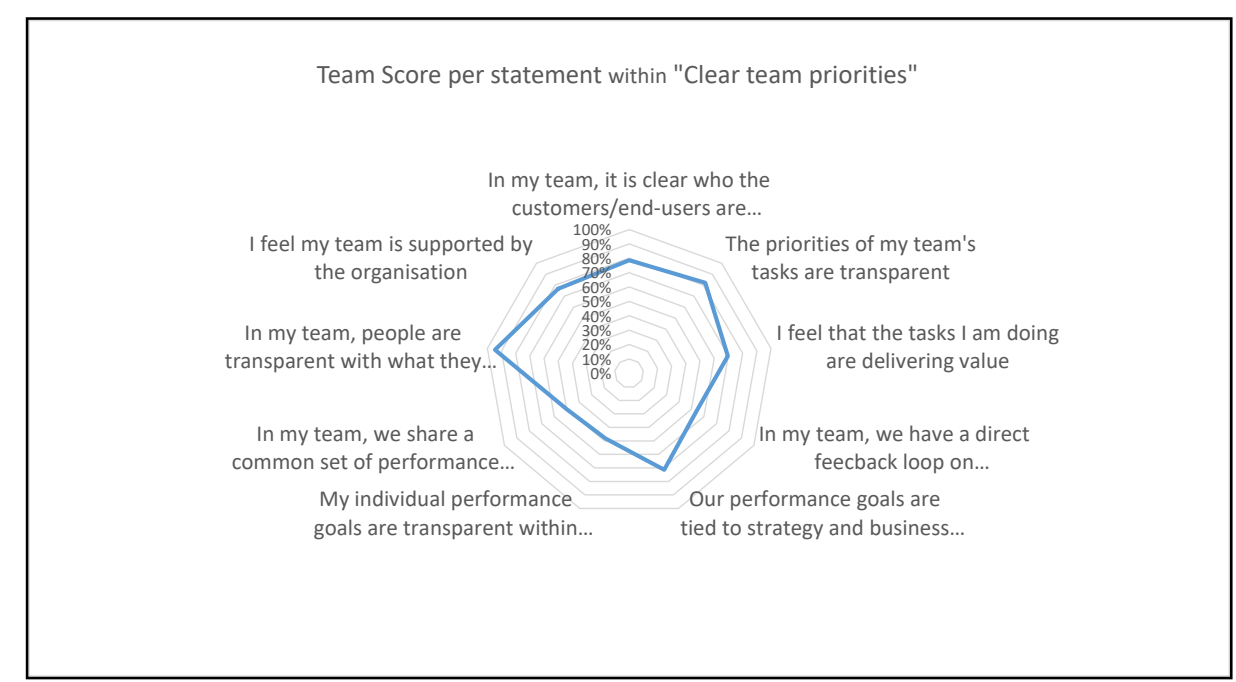

Fig. 2. Spider-web for the statements regarding the "clear team priorities" factor

The framework, the team insight tool, and the coached feedback session was evaluated in a pilot test of six teams consisting of 43 individuals in total. The pilot test created awareness among these teams on things that they realized needed improvement, and they then got onto that. Following the pilot, the survey statements were evaluated and an external vendor of "people surveys" provided suggestions for how to improve the set of statements. This clarified the scope of statements and removed ambiguities. This led to some restructuring of the framework bringing it to the form presented in this paper. In addition, a number of survey statements were modified.

Example survey statement in pilot version:

- Business and customer feedback are delivered to you and your team on a regular basis

Example survey statement in final version:

- In my team, we have a direct feedback loop on customer and end-user needs

Following the modifications, the solution was made available as an opportunity for all teams in the organization.

As of June 4, 2019, 29 teams of 252 individuals have used the "team insight" opportunity. On top of that, 32 teams of 289 individuals have used the "becoming a high performing team" opportunity.

Reception of these modules has broadly been very positive.

Examples of feedback:

- "The workshop helped me unify my team who worked in two cliques having a 'them-and-us' mentality" 
- "The Insights session actually confirmed what we ourselves thought were our weak points and afterwards it has been much easier for us to talk about our strengths and weaknesses."

- "The team identified specific actions to focus on and I'll strive to ensure that these are prioritized and that this type of retrospective becomes part of the team rhythm"

- "We have found great benefit from starting our journey towards high performing teams using the principles from the workshop - it is a really good way to openly discuss and improve as a team."

From the coach perspective, there were observations regarding how the teams received the spider-web data, which represented their own voice. As the feedback alludes, most teams appreciated the analysis and insight provided. A few teams, however, reacted as if they were in a state of denial, by explaining how they were high-performing despite they own data indicating room for improvement.

Follow up on agreed improvement is important for it to stick. Although the coaches have a role to play here, not all coaches have done the required follow up with the teams who have used the two offers.

\section{Evaluation}

In this section, we review some representative cases of the more than 50 teams who have used the Team Insight assessment. Overall, these showed a clear satisfaction of this opportunity provided by the company.

On 26 March 2019 we performed three interviews with representatives of three teams, who had used the facilitated Team Insight assessment feedback and in connection with this got facilitation or coaching. For the evaluation interviews, we had developed a questionnaire with 22 questions. These three interviews were supplemented with written response and quotes from three other users of the facilitated team assessment. The following descriptions and conclusions are based on the responses from six people on six different teams.

All teams were working with the development of different software-based solutions and the team size was from six to nine members. The teams differ regarding stability one team recently got new members, another team was established as a mix of two teams, and one team of people had worked together for many years. The full spectrum is represented.

There are several observations and lessons learned from the respondents:

- The expectations were either non-existent, skeptical or getting knowledge of what a high-performance team is. One hoped it could be used to demonstrate that the teams were high-performance teams, like when you get a "star" for good performance at school.

- All the respondents found it very easy to use the Team Insight tool as well as the facilitated part. Questions were easy to understand and answer, and the theories were translated into plain and comprehensible terms. Completing the questionnaire took 20 minutes. The principles, factors, theory and model behind the tool fulfil the needs for now, and no one had recommendations for improvements. There was a 
clear feeling that all eight principles needed to be there. Several expressed that there was a good balance between theory and practice.

- The introduction process, guaranteed anonymity and the open discussions at the workshop were viewed as exceptionally good by all teams.

- About half of the teams got ah-ha surprises during the facilitated assessment - surprising recommendations, which made good sense, and all expressed a sense of a much more informal atmosphere than normal. All teams expressed that the assessment result showed a true picture of the team's state and they received relevant and valuable recommendations based on the assessment.

- All teams expressed the follow-up on agreed improvements as beneficial and hoped it would continue and be more pro-active.

- There is a clear difference in how the teams defined actions. Two teams had defined actions, which are followed closely. One team did not have time for that yet, and the rest of the teams are in between.

- One clear shortcoming is the missing performance measurement. The teams were only able to follow an increase in productivity by looking at velocity, burn down or feedback. With successive assessments they can demonstrate a change in score of the principles and factors. They all articulate a lot of value and beneficial discussions - and describe positive changes. But it is currently not possible to quantify.

- Two of the interviewees expressed a desire to show a positive result (e.g., as a score) to management, but they also wanted their data to be anonymous and not comparable to that of the other teams.

- Two respondents raised the risk of not having enough time and focus to successfully change and improve.

A few quotations from the interviews express it all:

"It helps with changing the mind-set to become a High-Performance Team".

"The assessment clearly showed the differences in the team and the lack of regular retrospectives, interacting within the team as well as with target groups".

"It worked really well that it was so interactive and that there were also good links between the theory and the conclusions".

On average, the respondents evaluated the facilitated Team Insight assessment and theoretical workshop as eight on a scale from one to ten.

The overall conclusion is that the facilitated Team Insight assessment has been very beneficial for the teams, who gained good insight into the state of their team and received the groundwork for becoming higher performing. They have been able to change and improve their team collaboration - with a limited effort. Every respondent requests another assessment and continuous improvement of the team's performance and expressed their satisfaction with the opportunity provided by the company.

\section{$7 \quad$ Discussion and next steps}

We have now presented the HiPEFrame framework and our evaluation results. Overall, the application of the framework was a successful undertaking. If other organisations 
are inspired to do something similar, we can outline a number of steps for attempting to do so, so they may draw on our approach and learnings.

First, you need to recognise that you have a challenge - or a problem - with your teams. You also need to gather information, i.e., through interviews or a survey about the nature and details of the problem.

Second, you can take the eight factors that we built and critically reflect on whether they can be used for assessing a team in your organisation. You also need to consider what kind of training you will provide and whether you will use one or more of the team models that we used.

Third, you never get it right the first time, but you learn a lot. So plan for a pilot testing with 2-3 iterations following the basics of design thinking (Brown 2008; Dorst 2011)

Fourth, based on the learning from the design iterations you can create your final concept of training and assessment and roll it out in your organisation.

We have found it to be very important to have someone with the responsibility of following up. Thus, we recommend that you design a facilitated process - someone in charge of the rhythm. Furthermore, it is important that these facilitators have regular undertakings as coaches in order to stay sharp and be good facilitators. You should consider whether you will have a group of dedicated experts in your organisation for this - as we decided to have in Danske Bank.

Another important observation is that the teams, which are consistently successful at their business priorities, are those that set aside time for the necessary improvements. An assessment alone doesn't do the trick. You need to invest time in the improvement and everyone on the team must be involved in doing so. Furthermore, the key to success is to be able to create both awareness and desire in the teams. That is a job for the coaches.

In our research we have drawn inspiration from other published authors. The model of Lippert \& Dulewicz (2018) focuses mostly on operational aspects and nominate "schedule adherence", "budget adherence", "conflict resolution", "technical innovation", and "efficiency" as the primary performance parameters. (Elgamel 2018) takes a slightly different approach focusing more on the organisation than teams and individuals. Tan (2018) is the one closest to our model, whose paper also has an 8-dimensional model. We did find however, that their model misses out on the skills and rhythm aspects.

\section{Conclusion}

We have now presented the development of a team improvement concept to foster high performing teams in Danske Bank. We have presented the overall framework and details of how to apply it. Furthermore, we have presented examples and lessons learned and we have discussed how other organizations can organize a similar bootstrapping process. We conclude that you can "bootstrap" yourself to a higher performing team through facilitated self-assessments and carefully planned training. 
In relation to the SPI manifesto (Pries-Heje and Johansen 2010), we address the people issue, especially the principle of creating a learning organization. In fact, the bootstrapping process is a way of creating a learning team.

We believe the framework derived can be of value to other organizations - especially IT development organizations. As we took our starting point in existing literature and knowledge on efficient and optimal teams, we are certain that the answer to our research question in the form of the HiPEFrame framework and method of applying it - is an answer that other organizations will be interested in.

One of the things we have not mentioned in the paper are cultural differences. Danske Bank has major IT development organizations in Denmark, India and Lithuania. In relation to that, we have found that there are very interesting cultural differences between teams based in these three countries. That will be the topic of further research: how can the HiPEFrame be adapted to different cultures?

\section{References}

1. Adair, J. 1986. Action-Centred Leadership London: McGrawHill.

2. Albrecht, A. J. 1979. Measuring Application Development Productivity. Paper read at Proceedings form the Joint SHARE, GUIDE, and IBM Application Development Symposium, at Monterey, California, October 14-17.

3. Andreasen, M. E., and K. Sørensen. 2016. Learnings from high performing global teams in Group IT: Danske Bank.

4. Belbin, R. M. 2012. Team roles at work: Routledge.

5. Bion, W. R. 1961. Experiences in Groups and Other Papers. London.

6. Blanchard, K., D. Carew, and E. Parisi-Carew. 2000. One Minute Manager Builds High Performing Teams, The Rev: Harper Collins.

7. Boehm, B., C. Abts, A. W. Brown, S. Chulani, B. K. Clark, E. Horowitz, R. Madachy, D. J. Reifer, and B. Steece. 2000. Cost estimation with COCOMO II. ed: Upper Saddle River, NJ: Prentice-Hall.

8. Boehm, B. W., T. E. Gray, and T. Seewaldt. 1984. Prototyping versus specifying: a multiproject experiment. IEEE transactions on Software Engineering (3):290-303.

9. Brown, T. 2008. Design thinking. Harvard Business Review 86 (6):84.

10. Chiarini, A., C. Baccarani, and V. Mascherpa. 2018. Lean production, Toyota Production System and Kaizen philosophy: A conceptual analysis from the perspective of Zen Buddhism. The TQM Journal 30 (4):425-438.

11. Chrissis, M. B., M. Konrad, and S. Shrum. 2003. CMMI guidelines for process integration and product improvement: Addison-Wesley Longman Publishing Co., Inc.

12. Dorst, K. 2011. The core of 'design thinking' and its application. Design studies 32 (6):521532.

13. Drexler, A. B., D. Sibbet, and R. H. Forrester. 1988. The team performance model. In Team building, edited by W. B. Reddy and K. Jamison. Alexandria, Virginia, USA NTL Institute for Applied Behavioral Science.

14. Duhigg, C. 2016. What Google learned from its quest to build the perfect team. New York Times.

15. Dumke, R., and A. Abran. 2016. COSMIC Function Points: Theory and Advanced Practices: Auerbach Publications. 
16. Elgamel, M. A. 2018. Dynamic organizational capabilities: The joint effect of agility, resilience and empowerment. Journal of Human Resource Management 6 (2).

17. Forrester, R., and A. B. Drexler. 1999. A model for team-based organization performance. Academy of management executive 13 (3):36-49.

18. Hedaa, J. 2018. Nucleon - The Missing Formula That Measures Your It Development Team's Performance: CreateSpace Independent Publishing Platform.

19. Hevner, A. R. 2007. A three-cycle view of design science research. Scandinavian journal of information systems 19 (2):4.

20. Humphrey. 2006. TSP (SM) Coaching a Development Team: Pearson Education.

21. Humphrey, W. 1999. Introduction to Team Software Process. Massachusetts: Addison Wesley Professional.

22. Johnson, J. 2018. CHAOS Report: Decision latency theory: It is all about the interval. Lulu.com, 70.

23. Katzenbach, J. R., and D. K. Smith. 2015. The wisdom of teams: Creating the high-performance organization: Harvard Business Review Press.

24. Kelley, T. 2005. The ten faces of innovation: IDEO's strategies for beating the devil's advocate $\&$ driving creativity throughout your organization: Crown Business.

25. Lencioni, P. 2012. The advantage: Why organizational health trumps everything else in business: John Wiley \& Sons.

26. Lippert, H., and V. Dulewicz. 2018. A profile of high-performing global virtual teams. Team Performance Management: An International Journal 24 (3/4):169-185.

27. March, S. T., and G. F. Smith. 1995. Design and natural science research on information technology. Decision Support Systems 15 (4):251-266.

28. McChrystal, G. S., T. Collins, D. Silverman, and C. Fussell. 2015. Team of teams: New rules of engagement for a complex world: Penguin.

29. Morriss, P. 2002. Power: a philosophical analysis: Manchester University Press.

30. Pries-Heje, J., and J. Johansen. 2010. SPI Manifesto. EuroSPI Conference 2010: eurospi.net, 17.

31. Schneider, M. Google spent 2 years studying 180 teams. The most successful ones shared these 5 traits., 19 July 2017 [cited. Available from https://www.inc.com/michael-schneider/google-thought-they-knew-how-to-create-the-perfect.html.

32. Schutz, W. 1982. Elements of Encounter. edited by I. Publishers. New York.

33. Smart, B. D. 2005. Top grading: How leading companies win by hiring, coaching, and keeping the best people: Penguin.

34. Snabe, J., and M. Trolle. 2018. Dreams and Details: Gyldendal Business.

35. Tan, B. 2018. Developing a high performing senior leadership team. Training \& Development. www.aidt.com.au (March 2018):20-22.

36. Truss, C., A. Shantz, E. Soane, K. Alfes, and R. Delbridge. 2013. Employee engagement, organisational performance and individual well-being: exploring the evidence, developing the theory: Taylor \& Francis.

37. Tuckman, B. W. 1965. Developmental Sequence in Small Groups.

38. Venable, J., J. Pries-Heje, and R. Baskerville. 2016. FEDS: a framework for evaluation in design science research. European journal of information systems 25 (1):77-89.

39. Walls, J. G., G. R. Widmeyer, and O. A. El Sawy. 1992. Building an information system design theory for vigilant EIS. Information Systems Research 3 (1):36-59.

40. Weinberg, G. M., and E. L. Schulman. 1974. Goals and performance in computer programming. Human factors 16 (1):70-77.

41. Yin, R. K. 2017. Case study research and applications: Design and methods: Sage publications. 